\title{
ESTRATÉGIAS DE ENSINO DE RELAÇÕES ARBITRÁRIAS ENTRE ESTÍMULOS VISUAIS EM CÃES, ABELHAS E MACACOS-PREGO
}

\section{TEACHING STRATEGIES OF ARBITRARY RELATIONS TO DOMESTIC DOGS, BEES, AND CAPUCHIN MONKEYS}

\author{
ISABELA ZAINE - ORCID 0000-0003-0641-9761 \\ UNIVERSIDADE FEDERAL DE SÃO CARLOS, BRASIL \\ InSTITUTO NACIONAL DE CIÊNCIA E TECNOLOGIA SOBRE COMPORTAMENTO, COGNIÇÃo E ENSINO, BrasIL \\ UNIVERSIDADE DE SÃo PAULO, BRASIL \\ CAMILA DOMENICONI - ORCID 0000-0003-0486-3543 \\ UNIVERSIDADE FEDERAL DE SÃO CARLOS, BRASIL \\ InStITUto NACIONAL dE CIÊNCIA E TECNOLOGIA SOBRE COMPORTAMENTO, COGNIÇÃo E ENSINO, BRASIL \\ ANTONIO MAURÍCIO MORENO \\ UNIVERSIDADE FEDERAL de SÃo CARLos, BRASIL \\ InStITUTO NACIONAL DE CIÊNCIA E TECNOLOGIA SOBRE COMPORTAMENTO, COGNIÇÃo E ENSINO, BRASIL \\ UNIVERSIDADE ESTADUAL DO SUDOESTE DA BAHIA, BRASIL
}

\author{
ANA LEDA DE FARIA BRINO - ORCID 0000-0002-0687-9007 \\ UNIVERSIDADE FEDERAL DO PARÁ, BRASIL

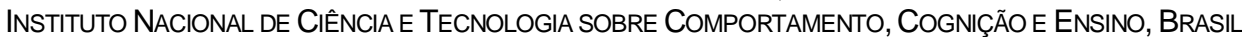

\section{RESUMO}

Determinar as condições em que um organismo aprende discriminações condicionais arbitrárias é um problema relevante aos psicólogos que trabalham com aprendizagem, uma vez que esse comportamento parece ser pré-requisito de uma infinidade de repertórios relacionais complexos. O presente trabalho descreve estudos de laboratórios integrados que aplicaram algumas estratégias alternativas de ensino de discriminações condicionais arbitrárias entre estímulos visuais com cães domésticos, abelhas e macacos-prego. As estratégias usadas foram: 1) Treino prévio de discriminações simples e reversões; 2) Escolha forçada; 3) Treino blocado; 4) Uso de distratores e inserção atrasada dos estímulos de comparação negativos; 5) Manipulação do posicionamento dos estímulos de comparação; 6) Modelagem de controle de estímulos; e 7) Alternância de contexto de exclusão e tentativa e erro. As características e justificativas para o uso de cada estratégia e seus efeitos sobre o responder de organismos dessas diferentes espécies são apresentados. De um modo geral, os procedimentos aplicados não foram suficientes para produzir repertório relacional arbitrário em cães e em abelhas, gerando desempenhos ao nível do acaso. Para os macacos, uma dentre duas estratégias foi suficiente, mas um treino muito extenso foi necessário para gerar o repertório.

Palavras-chave: estratégias de ensino, discriminações condicionais arbitrárias, cães, abelhas, macacos-prego.

\begin{abstract}
Determining conditions in which an organism learns conditional discriminations is a significant matter to psychologists who work with learning, since this behavior seems to be a prerequisite for multiple complex relational repertoires. The present work describes integrated laboratories studies that used some teaching strategies to establish visual-visual arbitrary relations in domestic dogs, bees and capuchin monkeys. The strategies were: 1) Simple discrimination training and reversions; 2) Forced choice; 3) Blocked-trial; 4) Use of distractors and delayed insertion of negative comparison stimuli; 5) Manipulation of comparison stimuli position; 6) Stimulus control shaping and, 7) Alternation between exclusion and trial and error training. The characteristics and reasons for the use of each strategy and their effects on the subjects' performances are presented. In general, the procedures were not sufficient to produce arbitrary relational repertoires in dogs and bees, generating performance to chance level. For the monkeys, one of two strategies were sufficient, but a very extensive training was required to generate the repertoire.

Keywords: teaching strategies, arbitrary conditional discriminations, dogs, bees, capuchin monkeys.
\end{abstract}

Apoios financeiros: Isabela Zaine: processo nº 2011/06288-0, Fundação de Amparo à Pesquisa do Estado de São Paulo (FAPESP); Antonio Maurício Moreno: processo no 2012/11004-4, Fundação de Amparo à Pesquisa do Estado de São Paulo (FAPESP). Camila Domeniconi, bolsa produtividade CNPq, processo número 304161/2015-2. E-mail para contato com autores: isabela.zaine@gmail.com

DOI: http://dx.doi.org/10.18542/rebac.v15i1.8326 
Determinar as condições em que um organismo aprende relações condicionais entre estímulos é um problema relevante aos que trabalham com aprendizagem, na medida em que esse comportamento parece ser pré-requisito de uma infinidade de repertórios relacionais complexos, como, por exemplo, o responder por identidade generalizada e a formação de conceitos ou categorias arbitrárias ou simbólicas (de Rose, 1993; de Rose \& Bortoloti, 2007; Galvão, Soares Filho, Barros, \& Souza, 2008; Sidman \& Tailby, 1982).

Repertórios relacionais de identidade e identidade generalizada foram observados, por exemplo, em macacos-prego (Barros, Galvão, \& McIlvane, 2002; Brino et al., 2014; Galvão et al., 2005; Santos, 2003), chimpanzés (Oden, Thompson, \& Premack, 1988), leões-marinho (Kastak \& Schusterman, 1994), cães (Kaminski, Tempelmann, Call, \& Tomasello, 2009) e abelhas (Brown et al., 1998; Giurfa et al., 2001). No entanto, em nossos laboratórios, temos encontrado bastante dificuldade em se estudar a formação de classes arbitrárias ou simbólicas entre estímulos com cães, macacos e abelhas como sujeitos, em função da dificuldade de se estabelecer a linha de base necessária aos testes de desempenhos emergentes, indicativos da formação das classes.

O objetivo do presente trabalho é descrever uma série de estudos conduzidos em nossos laboratórios integrados de pesquisa básica que aplicaram estratégias alternativas ao procedimento de ensino por tentativa e erro, visando o estabelecimento de discriminações condicionais arbitrárias entre estímulos visuais com cães domésticos (Canis familiaris), abelhas (Melipona rufiventris e Melipona quadrifasciata) e macacos-prego (Sapajus spp.).

No geral, esses estudos tinham o objetivo comum de aplicar estratégias alternativas que gerassem poucos erros durante o processo de aprendizagem, visando manter os sujeitos na tarefa e desfavorecer o estabelecimento de topografias de controle de estímulos inconsistentes com as planejadas, que poderiam contribuir para resultados negativos em testes futuros de desempenhos emergentes (McIlvane \& Dube, 2003). Para isso, estes estudos buscaram estratégias que estabeleciam primeiramente repertórios mais simples ou que partiam de repertório já presente no sujeito, para alcançar, gradualmente, o estabelecimento de repertórios mais complexos (Gil, Oliveira, \& McIlvane, 2011; Sidman \& Stoddard, 1967). A descrição realizada neste trabalho envolve tanto as características dos procedimentos aplicados quanto os repertórios produzidos individualmente. Essa descrição foi precedida, algumas vezes, pela apresentação de pesquisas da área, nas quais os estudos foram baseados.

A maioria das estratégias de ensino aplicadas não produziu resultados positivos de ensino de relações condicionais arbitrárias nestas espécies. Pode-se argumentar que uma coletânea de estudos que relatam procedimentos que não produziram o repertório planejado não é importante. No entanto, o detalhamento de procedimentos que falharam em produzir resultados positivos ou mesmo em gerar o repertório de linha de base é fundamental para o planejamento de novos procedimentos de ensino.

Além disso, o conhecimento científico depende de replicações diretas e sistemáticas de estudos para ser confiável (Laws, 2013) e a escassez de dados positivos de formação de classes em não humanos demanda replicações, na medida em que há possibilidade de que essa escassez esteja ocorrendo em função de falhas de procedimento (Dube \& McIlvane, 1996). Os detalhes de procedimentos provavelmente relevantes para a efetividade de ensino são muitos, e certamente variam para diferentes espécies em função de características biológicas, gerando a necessidade de relatos de pesquisa que esclareçam as diversas estratégias até então utilizadas com diferentes espécies.

As falhas de procedimento em ensinar relações arbitrárias não são particulares às pesquisas que trabalharam com não humanos. O problema já foi relatado por pesquisadores que estudam o comportamento de humanos com deficiência intelectual ou de crianças muito pequenas. Por exemplo, Dugdale e Lowe (1990) e Augustson e Dougher (1991) tiveram dificuldades em ensinar relações arbitrárias a crianças de 4 e 2 anos de idade, respectivamente, impedindo a aplicação de testes de desempenho emergente. Para construir conhecimento nessa área, um caminho parece ser um modelo translacional de replicação sucessiva e espiral de procedimentos entre populações que não aprendem discriminações condicionais arbitrárias com facilidade. Nesse sentido, os procedimentos aplicados com não humanos são algumas vezes provenientes da pesquisa com humanos e vice-versa.

Faz parte de o empreendimento científico testar repetidamente e a geração de resultados negativos é produto provável de replicações e também forma a base de dados empíricos que pode guiar a formulação de novos procedimentos na área.

\section{Procedimentos adotados e resultados obtidos}

A seguir, são apresentadas as estratégias de ensino usadas em nossos laboratórios integrados de pesquisa básica, iniciando-se alguns dos tópicos com uma breve descrição dos estudos originais que serviram de base aos procedimentos aqui relatados, seguida pela descrição de detalhes dos procedimentos aplicados por nosso grupo de pesquisa e dos resultados obtidos com macacos-prego, abelhas e cães. Todos os estudos foram aprovados por comitês de ética em pesquisa com animais, quando pertinente 1 . A Tabela 1 apresenta uma esquematização dessas estratégias, respectivos resultados e as topografias de controle de estímulos observadas, dados que serão descritos a seguir.

1 Estudos com cães: CEUA/UFSCar 033/2012; estudos com macacos: CEPAE UFPA PS001/2005. Estudos com invertebrados, como no caso das abelhas, dispensam aprovação de Comitês de Ética. 
Tabela 1

Recursos experimentais usados em treinos de discriminações condicionais com cães, abelhas e macacos, e resumo dos resultados obtidos.

\begin{tabular}{|c|c|c|c|c|c|}
\hline \multirow[t]{2}{*}{ Recurso Experimental } & \multicolumn{3}{|c|}{ Espécies } & \multirow{2}{*}{$\begin{array}{l}\text { Aprendizagem de } \\
\text { relações } \\
\text { condicionais }\end{array}$} & \multirow{2}{*}{$\begin{array}{l}\text { Topografias de controle de } \\
\text { estímulos observadas }\end{array}$} \\
\hline & Cães & Abelhas & Macacos & & \\
\hline $\begin{array}{l}\text { 1. Treino prévio de } \\
\text { discriminação simples } \\
\text { e reversões }\end{array}$ & & $\mathrm{X}$ & & Não. & $\begin{array}{l}\text { Não foi possível identificar } \\
\text { topografias nítidas }\end{array}$ \\
\hline 2. Escolha forçada & $\mathrm{X}$ & & & Não. & $\begin{array}{l}\text { Não foi possível identificar } \\
\text { topografias nítidas }\end{array}$ \\
\hline 3. Treino blocado & $\mathrm{X}$ & $\mathrm{X}$ & & $\begin{array}{l}\text { Não. Apenas } \\
\text { reversões cada vez } \\
\text { mais rápidas. }\end{array}$ & $\begin{array}{l}\text { Cães: controle pela posição } \\
\text { ocupada pelos estímulos } \\
\text { Abelhas: Não foi possível } \\
\text { identificar topografias nítidas }\end{array}$ \\
\hline $\begin{array}{l}\text { 4. Uso de distratores } \\
\text { e inserção atrasada de } \\
\text { comparações } \\
\text { negativos }\end{array}$ & $\mathrm{X}$ & & & Não. & $\begin{array}{l}\text { Preferência por um dos } \\
\text { estímulos de comparação }\end{array}$ \\
\hline $\begin{array}{l}\text { 5. Manipulação do } \\
\text { posicionamento dos } \\
\text { estímulos de } \\
\text { comparação }\end{array}$ & $\mathrm{X}$ & & & $\begin{array}{l}\text { Não. Apenas } \\
\text { controle por } \\
\text { posição eliminado. }\end{array}$ & $\begin{array}{l}\text { Preferência por um dos } \\
\text { estímulos de comparação }\end{array}$ \\
\hline $\begin{array}{l}\text { 6. Modelagem de } \\
\text { controle de estímulos }\end{array}$ & & & $\mathrm{X}$ & $\begin{array}{l}\text { Parcial. Contudo, } \\
\text { procedimento } \\
\text { pouco econômico. }\end{array}$ & $\begin{array}{l}\text { Louis - Não houve testes de } \\
\text { verificação de relações de } \\
\text { controle; Guga e Raul - } \\
\text { Controle pelas partes de } \\
\text { modelo que se mantinham } \\
\text { idênticas ao comparação e } \\
\text { vice-versa }\end{array}$ \\
\hline $\begin{array}{l}\text { 7. Alternância de } \\
\text { contexto de exclusão } \\
\text { e tentativa e erro }\end{array}$ & & & $\mathrm{X}$ & $\begin{array}{l}\text { Parcial. Responder } \\
\text { condicional } \\
\text { estabelecido com } \\
\text { um macaco, mas } \\
\text { não com o outro. }\end{array}$ & $\begin{array}{l}\text { Não foram aplicados testes de } \\
\text { verificação de relações de } \\
\text { controle, mas houve indício } \\
\text { de preferência por estímulo }\end{array}$ \\
\hline
\end{tabular}

\section{1) Treino prévio de discriminação simples e reversão} Essa estratégia aqui utilizada com abelhas foi baseada em estudo prévio de Goulart, Galvão e Barros (2003), com macacos-prego como sujeitos. Os macacos eram expostos a um treino de discriminações simples combinadas e reversões, por exemplo, tentativas de A1 $(\mathrm{S}+)$ e A2 (S-), e B1 (S+) e B2 (S-) eram alternadas em uma sessão. Quando era atingido um critério de aprendizagem, era realizada a reversão da função dos estímulos, e A2 e B2 passavam a funcionar como S+ e A1 e B1, como S-. Atingido o critério de aprendizagem, iniciava-se nova reversão, e assim sucessivamente. Essa fase era encerrada quando era atingido o critério de seis respostas corretas consecutivas em, no máximo, oito tentativas em três reversões sucessivas.

Em um dos estudos cujos dados são relatados no presente manuscrito, dez abelhas (Melipona quadrifasciata) foram treinadas a discriminar entre luz azul e luz amarela ou entre luz branca e lâmpada apagada, como preparação para a tarefa de emparelhamento arbitrário ao modelo. O treino de discriminação simples era conduzido em blocos de 10 tentativas. Ao final de um bloco de tentativas, se fosse atingido o critério de $80 \%$ de respostas corretas ( 8 tentativas), era iniciado um bloco de tentativas da fase seguinte, de reversão da discriminação.

$O$ treino da primeira reversão de discriminação era também formado por blocos de 10 tentativas. Assim como na fase de estabelecimento da discriminação simples, o critério de finalização da reversão exigia, pelo menos, oito respostas corretas. Tendo sido atingido esse critério, iniciava-se imediatamente a segunda reversão de discriminação. Neste, o treino era formado por blocos de 6 tentativas, com critério de encerramento de, pelo menos, 5 respostas corretas $(83,3 \%)$. O mesmo foi definido para a terceira reversão. Na quarta reversão, eram apresentados blocos de 4 tentativas com critério de encerramento de pelo menos três respostas corretas.

Seguindo esse protocolo, o número total de tentativas de treino com cada sujeito variou entre 98 e 324 . Os melhores resultados foram obtidos com duas das dez abelhas que aprenderam a tarefa de discriminação simples e, em seguida, aprenderam três reversões de discriminação. Contudo, todas as abelhas abandonaram a situação experimental antes que fosse possível observar o 
estabelecimento de controle pelos estímulos condicionais ao longo das reversões de discriminações simples.

Em outro estudo, duas abelhas (M. quadrifasciata) receberam treino de discriminação simples e reversão de discriminação, e, em seguida, treino de discriminação condicional com os mesmos estímulos. Neste experimento, uma luz foi usada com a função de estímulo condicional. Em uma fase inicial do procedimento, cada abelha recebia treino de discriminação simples e reversão de discriminação, de modo similar ao procedimento descrito acima, seguido pelo treino de discriminações condicionais. Como resultado, uma das duas abelhas aprendeu a tarefa de discriminação simples e atingiu critério em oito reversões de discriminação, em aproximadamente 700 tentativas de treino. No entanto, ao receber o treino de discriminações condicionais, essa abelha respondeu ao nível do acaso ao longo de aproximadamente 350 tentativas (ver Figura 1).
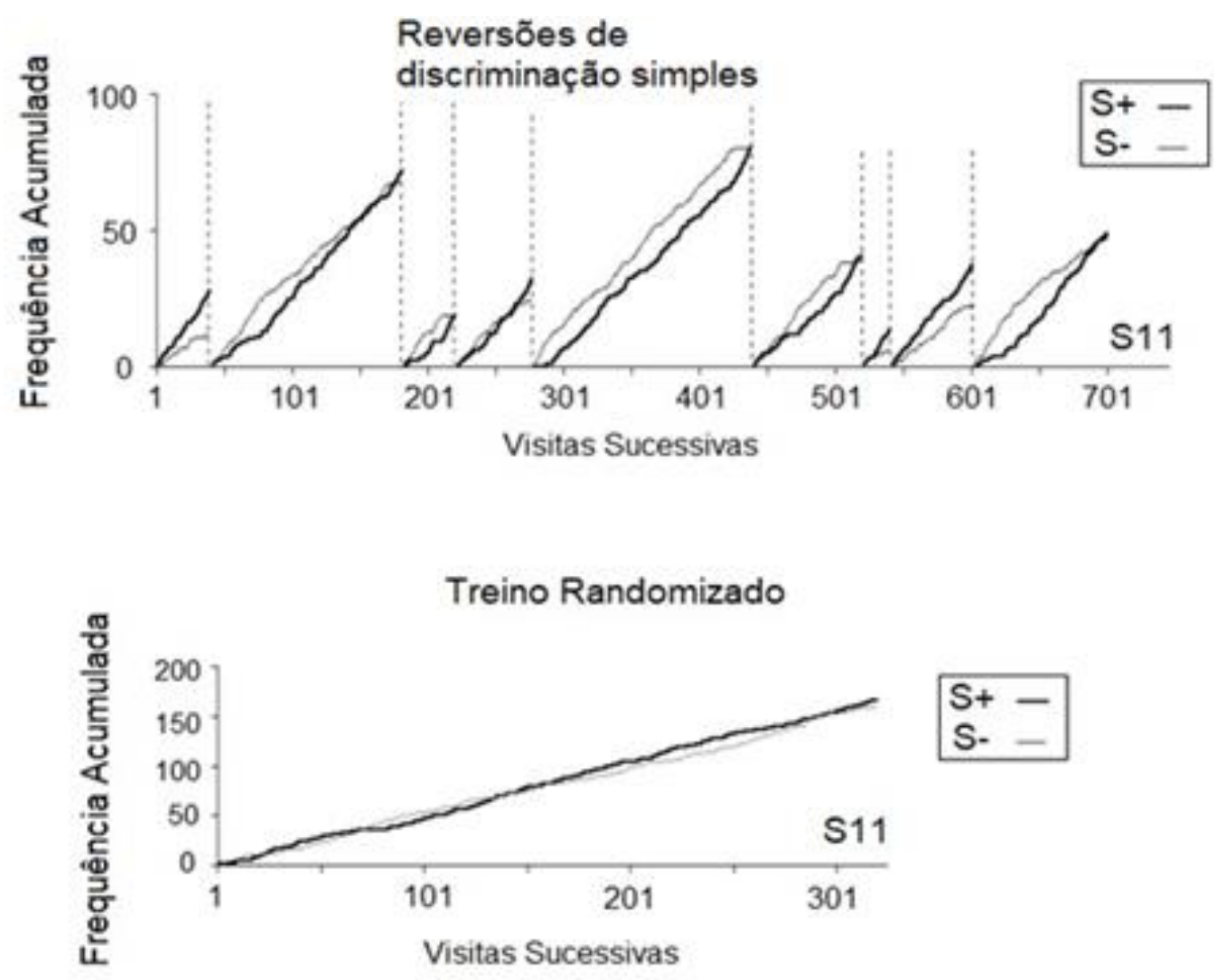

Figura 1. Painel superior: Frequência acumulada de respostas corretas (linha grossa e escura) e de respostas incorretas (linha clara e fina) em um treino de discriminação condicional com uma abelha. Lâmpada acesa e lâmpada apagada funcionavam como estímulo condicional; lâmpada azul e lâmpada amarela funcionavam como estímulos de comparação. Em um bloco, o mesmo estímulo condicional era apresentado em todas as tentativas. O estímulo Azul era o S+ inicial. A alternação entre lâmpada acesa e lâmpada apagada era feita quando era atingido o critério de seis acertos consecutivos. Cada linha pontilhada representa uma alternação entre estímulos condicionais. Painel inferior: discriminações condicionais com alternação entre os modelos em sequência semi-randomizada (a alternação entre estímulos modelo era randomizada, com a condição de que um mesmo modelo era apresentado em no máximo três tentativas consecutivas).

O uso da estratégia de discriminações simples e reversão se apoia na hipótese de que a aquisição de um repertório mais complexo, como o de discriminações condicionais, deve ocorrer posteriormente à aquisição de um repertório mais simples, de discriminações simples e reversão de discriminação. Os resultados desses dois estudos com as abelhas indicam que o procedimento de discriminações simples e reversão não funcionou como condição facilitadora à aprendizagem de relações condicionais, e que a maioria das abelhas não atingiu critérios de aprendizagem nas fases de reversão de discriminação simples. Os resultados obtidos por Goulart et al. (2003), no estudo com macacos, apresentaram grande variabilidade e os autores também concluíram que o procedimento de discriminação e reversão foi insuficiente para produzir classes em dois macacos-prego.

Nesse sentido, parece justificado o uso das estratégias descritas a seguir nos Tópicos 2 e 3, de escolha forçada e de treino blocado, que apresentam 
tentativas de treino de discriminações condicionais desde o início do protocolo de ensino.

\section{2) Escolha forçada}

Os relatos de desempenho de cães apresentados a seguir referem-se a dados coletados com três cadelas adultas, Sally e Pitty, com 3 anos de idade, da raça poodle toy, e Pituca, com 4 anos, sem raça definida (detalhes podem ser vistos em Zaine, 2015). Os estímulos visuais eram objetos tridimensionais (por exemplo, brinquedos de cachorro), de diferentes cores, tamanhos e materiais. O objetivo era o estabelecimento de relações condicionais entre dois pares de estímulos (A1B1 e A2B2) e a resposta requerida dos cães era a de tocar um dos estímulos disponíveis com o focinho.

Com a finalidade de reduzir a probabilidade de erros até o estabelecimento do repertório planejado, foi adotado um procedimento de escolha forçada. Nesse caso, diante de cada estímulo modelo, somente o estímulo de comparação positivo estava disponível para a escolha. Em uma sessão composta por 24 tentativas, as 12 primeiras apresentavam o estímulo A1 como modelo e somente o estímulo B1 como comparação, e as 12 últimas apresentavam A2 como modelo e B2 como comparação. Os estímulos de comparação variavam entre três posições fixas, previamente definidas a cada tentativa. O critério de aprendizagem nessa fase era de $100 \%$ de acertos em uma sessão.

As tentativas de escolha forçada tornavam altamente provável que os sujeitos emitissem a resposta correta porque a única alternativa à emissão da escolha do estímulo de comparação positivo era não responder. A estratégia de escolha forçada também era vantajosa por familiarizar os sujeitos à situação experimental, à cadeia de resposta de observação seguida pela resposta de escolha, e por facilitar o fortalecimento do engajamento na tarefa, de modo que o sujeito continuasse respondendo por várias tentativas seguidas. De fato, essa estratégia de treino foi bem-sucedida para familiarizar o sujeito à situação experimental e ao tipo de resposta exigido, uma vez que as três cadelas atingiram o critério de aprendizagem em apenas uma sessão de treino desse tipo.

Porém, o procedimento não se mostrou eficiente para favorecer o estabelecimento de discriminações condicionais em fases subsequentes do treino (como descrito no tópico a seguir - Treino blocado). Quando a escolha forçada foi removida e dois estímulos eram apresentadas como comparações, o desempenho dos sujeitos caiu ao nível do acaso, variando entre $40 \%$ e $60 \%$ de acertos. Assim, as tentativas de escolha forçada não foram suficientes para gerar respostas sob controle condicional dos estímulosmodelo, sendo que simplesmente gerou uma resposta generalizada de tocar com o focinho qualquer estímulo presente. Neste caso, após a remoção das tentativas de escolha forçada, a segunda fase do procedimento era de discriminações condicionais simultâneas em que os dois estímulos de comparação ( $\mathrm{S}+\mathrm{e} \mathrm{S}$-) estavam disponíveis para a escolha. A ordem de apresentação dos modelos, tentativa a tentativa, seguiu em treino blocado, descrito em detalhes no tópico a seguir.

\section{3) Treino blocado}

O procedimento de treino blocado aqui relatado foi baseado, com algumas diferenças, no estudo de Pessotti (1981), desenvolvido com abelhas, e no estudo de Saunders e Spradlin (1989), com adultos com deficiência intelectual. Em um procedimento "típico" de emparelhamento ao modelo, o produto esperado do procedimento é que o sujeito escolha o estímulo de comparação definido, condicionalmente a um dado modelo. Os modelos se alternam no decorrer das tentativas, e, por consequência, a função dos estímulos de comparação, sendo que a variação sucessiva do estímulo que deve ser escolhido para que haja reforço pode dificultar a aprendizagem da tarefa. Para reduzir a dificuldade de aquisição da tarefa, uma alternativa é organizar o treino em blocos de tentativas da mesma relação, de modo que apenas um estímulo modelo seja apresentado. O número de tentativas desses blocos é gradualmente reduzido conforme os critérios de aprendizagem vão sendo atingidos. Neste trabalho, o arranjo de treino blocado foi utilizado com cães (Canis familiaris) e abelhas (M. quadrifasicata e M. rufiventris).

No estudo com cães, os sujeitos foram as mesmas cadelas, Pitty, Sally e Pituca, que haviam passado pelo procedimento de escolha forçada previamente descrito. Os estímulos usados foram os mesmos do procedimento de escolha forçada. Os estímulos de comparação eram posicionados, a cada tentativa, em duas de três posições fixas alinhados entre si (P1: esquerda; P2: centro; P3: direita). O número de vezes em que o estímulo positivo ocupava cada uma das posições foi igualmente balanceado. Foram conduzidos blocos alternados de quatro tentativas com cada um dos modelos, num total de 24 tentativas por sessão. Por exemplo, quatro tentativas de treino da relação condicional A1B1 eram seguidas por quatro tentativas de treino da relação condicional A2B2. Na sequência havia novamente outras quatro tentativas do tipo A1B1, e assim sucessivamente, independentemente da quantidade de acertos em cada bloco. Caso o desempenho das cadelas permanecesse numa porcentagem de acertos menor ou igual a $75 \%$ em 5 de 6 sessões consecutivas, a estrutura de organização das tentativas seria modificada para blocos de 12 tentativas seguidas com um mesmo estímulo servindo como modelo, para que a contingência de reforçamento fosse mantida constante por um maior número de tentativas seguidas, com o objetivo de diminuir a quantidade de erros e a evitar baixa densidade de reforçamento e possível extinção do responder. O critério de aprendizagem para a passagem do treino blocado ao procedimento "típico" de emparelhamento permitia, no máximo, quatro erros em três de quatro sessões consecutivas, distribuídos entre as duas relações (A1B1 e A2B2).

Foram realizadas, em média, 24 sessões de treino blocado (a depender da disponibilidade das cadelas para a coleta), com número médio de 576 tentativas de treino. No entanto, a porcentagem de acertos das cadelas 
manteve-se ao nível do acaso, oscilando entre $40 \%$ e $60 \%$. Assim, apesar do número elevado de tentativas realizado, tal procedimento não foi suficiente para o estabelecimento de discriminações condicionais. Ao invés de um responder controlado pelos estímulos condicionais, todas as cadelas, em algum ponto do treino, responderam sob controle das posições ocupadas pelos estímulos de comparação, mais especificamente, sob controle da posição relativa entre os dois estímulos de comparação (por exemplo, responder em maior probabilidade ao estímulo localizado mais à esquerda em relação às posições ocupadas). A Figura 2 apresenta as porcentagens de respostas corretas de cada uma das cadelas no treino blocado, bem como as porcentagens de respostas sob controle das posições ocupadas pelos estímulos de comparação. Observa-se que houve uma tendência de as cadelas responderem em alta probabilidade (maior que $70 \%$ ) aos estímulos que ocupavam a posição relativa (PR) da direita ou da esquerda. Sally, por exemplo respondeu à PR esquerda entre $90 \%$ e $100 \%$ das tentativas das sessões 3 a 7 . A partir da sessão 8, passou a responder em maior probabilidade à PR direita (variando de 70\% a 95\%), em especial entre as sessões 19 e 25 . Pitty apresentou majoritariamente preferência por responder à PR esquerda, em especial das sessões 3 a 11 e nas duas últimas sessões. Já Pituca apresentou controle mais tênue por posições, no entanto, apresentou alguma preferência pela PR direita (sessões, 3, 5, 12, 13 e 15).
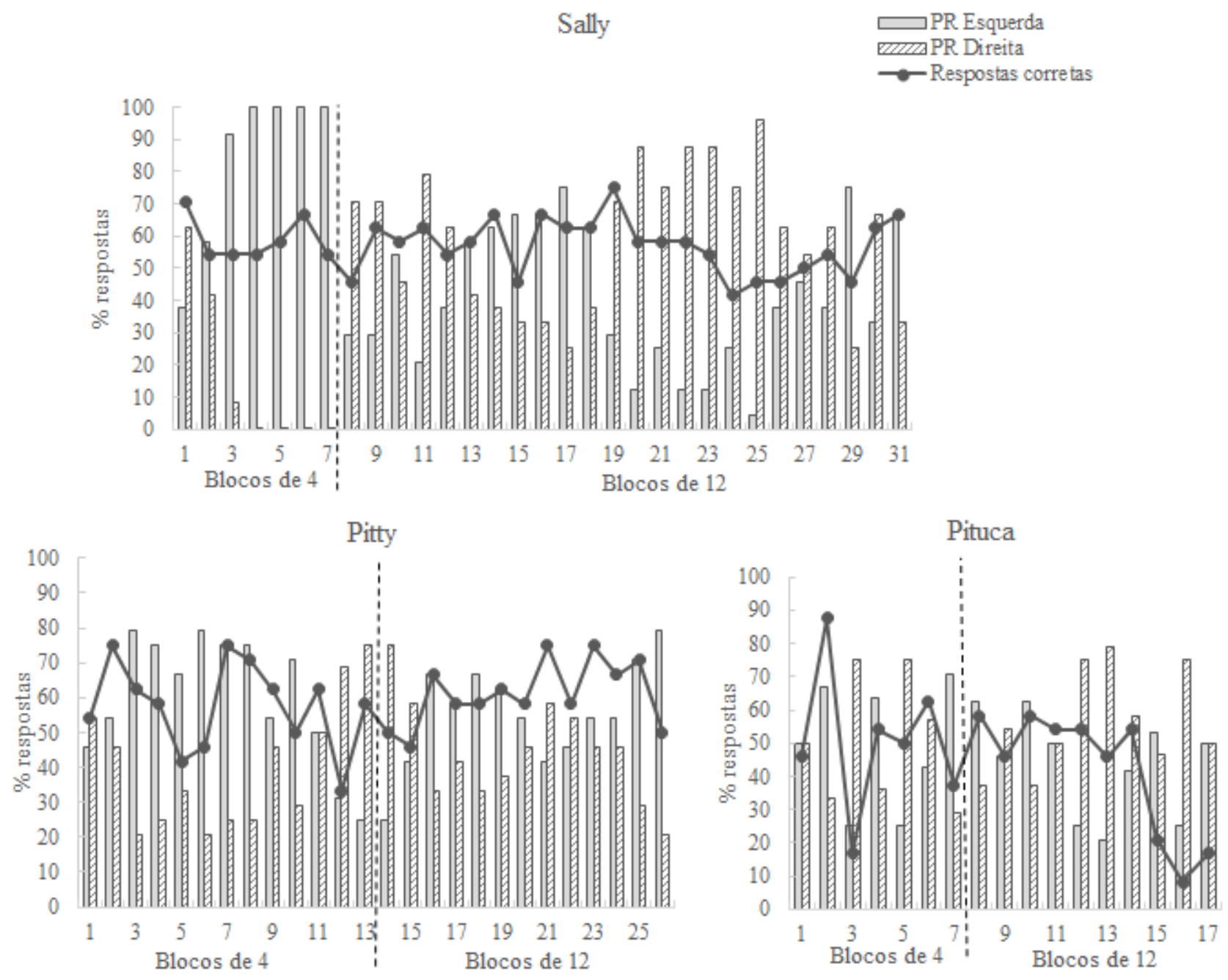

Figura 2. Porcentagens de respostas corretas de cada cadela no treino blocado e porcentagem de respostas sob controle das posições ocupadas pelos estímulos de comparação. PR: posição relativa. Nota: no treino blocado os estímulos de comparação ocupavam posições fixas (esquerda, central ou direita).

No treino blocado com abelhas, desenvolvido nesta série de estudos, blocos de cinco tentativas do tipo A1B1 eram alternados com blocos de cinco tentativas do tipo A2B2. A tarefa consistia em relacionar as cores (azul e amarelo) a padrões (horizontais e verticais) em preto e branco. Diferentemente do procedimento adotado com os cães, aqui, a alternação entre os blocos dependia de um critério de aprendizagem de $100 \%$ de acertos em 
cada bloco de treino. Com uma de quatro abelhas, observou-se a redução gradual na quantidade de erros a cada bloco de tentativas. Contudo, essa abelha recebeu aproximadamente 1000 tentativas de treino nessa condição, durante cerca de três semanas. Assim, esse procedimento mostrou-se pouco econômico e impraticável com abelhas porque, tipicamente, uma abelha se mantém respondendo em uma situação experimental até, no máximo, duas semanas.

Os treinos blocados dos cães e abelhas relatados acima foram semelhantes quanto ao número de tentativas por bloco, mas diferiram quanto ao critério de aprendizagem para a alternação entre os blocos (100\% de acertos em um bloco para as abelhas, e alternância independente de critério de aprendizagem em cães).

\section{4) Uso de distratores e inserção atrasada dos estímulos de comparação negativos}

Em um emparelhamento tradicional do tipo A1B1 e A2B2, os comparações podem ser sempre os estímulos B1 e B2, que devem ser condicionalmente selecionados diante dos respectivos modelos do Conjunto A. No entanto, a tarefa pode ser facilitada caso sejam também usados, dentre os comparações, estímulos que sirvam como distratores, que são perceptivelmente diferentes dos estímulos-alvo e podem facilitar a discriminação (Browder \& Lalli, 1991). Estímulos distratores sempre possuem função negativa (S-) no treino discriminativo, ou seja, sua escolha nunca é reforçada.

$\mathrm{Na}$ investigação com cães dessa série de estudos, as cadelas Pitty e Sally, que já haviam passado pelos procedimentos de escolha forçada e treino blocado, previamente descritos, foram expostas a esta estratégia. Pituca não participou dessa nova fase de treino por indisponibilidade dos donos para a coleta de dados. Esta estratégia ainda tinha como objetivo de estabelecer relações condicionais arbitrárias entre dois pares de estímulos visuais A1B1 e A2B2. Para evitar interferência de história de reforçamento prévia, os estímulos visuais utilizados foram estímulos novos, diferentes dos utilizados nos procedimentos anteriormente descritos e foram usados quatro estímulos de comparação, em que um deles tinha função positiva e os outros três, negativa, a depender do modelo. Cada sessão de treino também era composta por 24 tentativas e o critério de aprendizagem permitia, no máximo, quatro erros em três de quatro sessões consecutivas, distribuídos entre as duas relações. Juntamente com esta estratégia, os estímulos de comparação não mais ocupavam posições fixas, como nos estudos anteriormente mencionados, mas sim, eram livremente posicionados dentro de uma área pré-estabelecida (como descrito em detalhes na estratégia 5 apresentada a seguir).

Em cada sessão de treino, somente um estímulo modelo, por exemplo, A1, era apresentado. Nas quatro primeiras tentativas, apresentava-se somente o estímulo correto, B1, como comparação (escolha forçada); nas quatro tentativas seguintes, mantinha-se B1 e introduzia-se o distrator X1, sempre com função negativa; nas quatro tentativas seguintes, mantinha-se B1, X1 e acrescentava-se X2, também com função negativa; e, finalmente, a partir da $12^{\mathrm{a}}$ tentativa, inseriase B2, e todos os estímulos de comparação possíveis ficavam disponíveis às cadelas. $O$ critério de aprendizagem era de uma sessão com no máximo dois erros $(95,8 \%$ de respostas corretas). Em seguida, realizava-se um treino da segunda relação condicional, A2B2, em que somente A2 servia como modelo e os estímulos de comparação negativos eram introduzidos, também de maneira gradual. No entanto, como no treino precedente $\mathrm{A} 1 \mathrm{~B} 1$, a resposta reforçada fora responder em $\mathrm{B} 1$, no treino $\mathrm{A} 2 \mathrm{~B} 2$, o estímulo $\mathrm{B} 1$, agora negativo, foi sendo introduzido de maneira ainda mais gradual: nas duas primeiras sessões B1 só era incluído nas quatro tentativas finais do treino, na terceira sessão, B1 era incluído nas seis tentativas finais; na quarta sessão, nas dez últimas tentativas e, finalmente, a partir da sexta sessão, B1 passava a estar disponível a partir da $12^{\mathrm{a}}$ tentativa, como no treino A1B1. Após o critério de aprendizagem ser atingido, a situação de treino passava a apresentar a configuração habitual de um treino de emparelhamento "típico", com alternância em igual probabilidade entre os estímulos modelos A1 e B1 e presença de todos os estímulos de comparação (inclusive os distratores).

No entanto, o uso de distratores e a inserção atrasada dos estímulos negativos não favoreceu o estabelecimento das relações condicionais previstas. Apesar de as cadelas haverem atingido o critério de aprendizagem dos treinos separados A1B1 e A2B2, ao passarem para a fase subsequente de treino de emparelhamento "típico" a média de respostas corretas não ultrapassou 60\% (Sally: 59\%; Pitty: 53\%). Durante todo o treino de emparelhamento típico, Sally apresentou alta probabilidade de responder ao estímulo B2, a despeito do modelo, em especial nos primeiros dois terços do treino. É provável que a preferência por B2 nesta fase do treino tenha sido provocada pela fase anterior, em que somente A2 servia como modelo. Naquele caso responder em B2 era reforçado. Assim, a cadela manteve o mesmo padrão de resposta sob controle do estímulo de comparação com história de reforçamento mais recente, sem ficar sobre controle dos modelos alternativos. Pitty, por sua vez, apresentou preferência por um ou outro estímulo de comparação em momentos diferentes do treino. Assim como Sally, apresentou preferência pelo estímulo B2 na primeira metade do treino. No entanto, mais ao final do treino (a partir da sessão 60), passou a responder ao estímulo B1 em alta probabilidade. Estes dados podem ser observados na Figura 3.

Uma possibilidade de treino promissor seria o uso de distratores e inserção atrasada de $S$-, juntamente com o treino blocado, composto por um número menor de tentativas de cada relação por bloco, alternadas após critério de acertos consecutivos. Esta é uma combinação de estratégias a ser ainda implementada com as cadelas. 
5) Manipulação do posicionamento dos estímulos de comparação (posição fixa vs. livre)

Os resultados com cães anteriormente apresentados no treino blocado demonstraram forte controle pelas posições relativas ocupadas pelos estímulos de comparação (ver Figura 2). Tal controle por posições já foi apontado por estudos anteriores, com pombos (Cumming \& Berryman, 1961), macacos (Costa, 2008; Iversen, Sidman, \& Carrigan, 1986) e cães (Dahás et al., 2010).

Para desfavorecer o estabelecimento de controle por posição nos treinos discriminativos, com duas das três cadelas, Sally e Pitty, foi adotada a estratégia de posicionamento livre dos estímulos de comparação, relatado por Kaminski, Call e Fischer (2004), Kaminski et al. (2009) e Pilley e Reid (2011). Tal estratégia foi aplicada juntamente com a estratégia descrita na Seção 4 (uso de distratores e inserção atrasada dos estímulos de comparação negativos), de modo que a quantidade de tentativas por sessão e os critérios de aprendizagem eram os mesmos apresentados no referido tópico. Para tanto, delimitou-se uma área da sala experimental na qual os estímulos de comparação eram distribuídos ao acaso em qualquer posição disponível, sendo que as posições ocupadas por cada estímulo variavam de tentativa a tentativa, modificando-se a configuração geral de apresentação das escolhas.

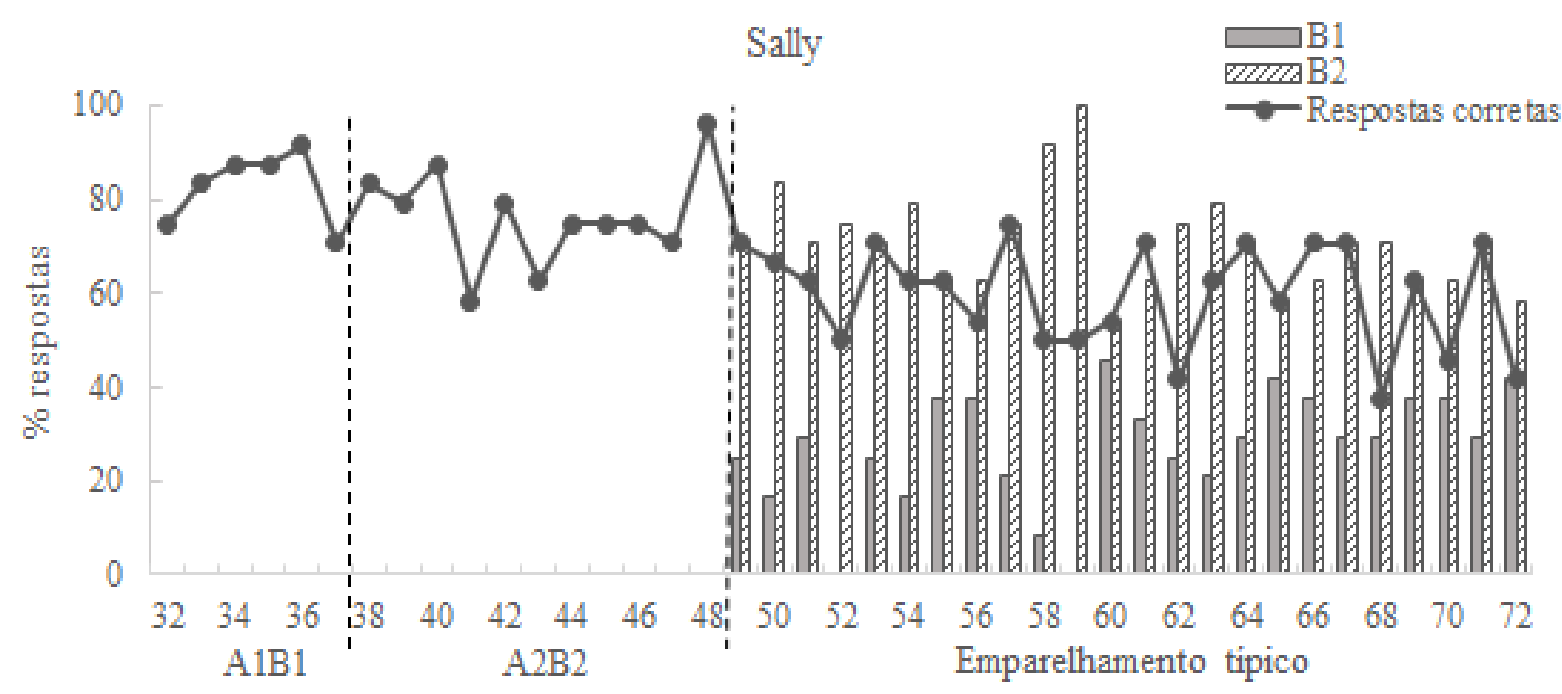

Pitty

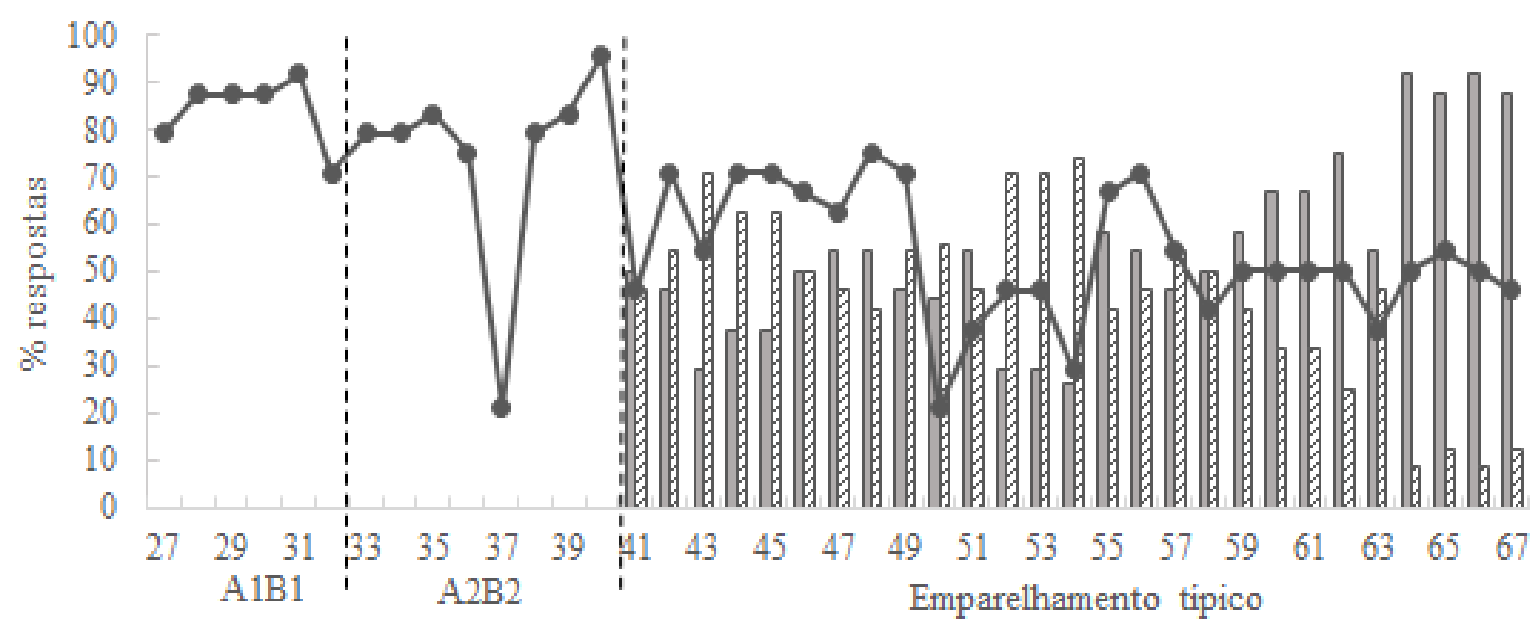

Figura 3. Porcentagens de respostas corretas de cada cadela no treino A1B1, A2B2 e no treino de emparelhamento típico e porcentagem de respostas sob controle de preferência de estímulos (B1 ou B2) no treino de emparelhamento típico. Nota 1: o número de sessões é uma continuidade da sequência seguida pelas estratégias anteriormente apresentadas no texto e na Figura 2. Nota 2: os estímulos de comparação ocupavam posições livres.

O posicionamento livre mostrou-se eficaz em eliminar o controle por posições. No entanto, como apresentado na Seção 4, as cadelas passaram a responder sob controle da preferência por um dos estímulos de comparação, inicialmente respondendo ao estímulo com história de reforçamento mais recente. Assim, a eliminação das posições fixas dos estímulos de comparação resolveu o problema de controle por posições, 
no entanto não foi suficiente para estabelecer controle condicional. Diante desses resultados, recomenda-se com cães que posições fixas sejam evitadas e que o uso de posicionamento livre seja combinado a outras características de treino para produzir controle condicional.

\section{6) Modelagem de controle de estímulos}

Com três macacos-prego como sujeitos (Louis, Guga e Raul), dois tipos de procedimento de modelagem de controle de estímulos (Dube \& McIlvane, 1996; McIlvane \& Dube, 1992) foram utilizados para o ensino de relações arbitrárias: Louis e Guga foram expostos ao procedimento de modelagem do modelo relatado em Brino et al. (2011) e em Cruz, Kataoka, Costa, Garotti, Galvão e Barros (2009), e Raul foi exposto à modelagem dos estímulos de comparação, relatado em Brino, Galvão, Barros, Goulart e McIlvane (2012). Em função de que esses sujeitos apresentavam identidade generalizada (Galvão et al., 2005) e já respondiam, portanto, sob controle condicional, todos os procedimentos de modelagem de controle de estímulos para o treino arbitrário tinham como etapa inicial um treino de emparelhamento ao modelo por identidade. Durante os passos do procedimento de modelagem, um dos estímulos (modelo ou comparação) sofria transformações graduais que eram efetuadas mediante critério de desempenho em cada passo. No passo final, os pares de estímulos, inicialmente idênticos, passavam a diferir, caracterizando o treino de relações arbitrárias. $\mathrm{O}$ critério para avanço de passo geralmente exigia desempenho igual ou acima a $90 \%$ de acertos em uma sessão.

Para o sujeito Louis, realizou-se uma replicação do procedimento de modelagem do modelo de Zygmont et al. (1992), realizado com indivíduos com deficiência intelectual. O procedimento envolveu a transformação gradual de cada estímulo modelo (ver detalhes na Figura 1 de Brino et al., 2011, p. 390). Os resultados são apresentados na Figura 2 do Experimento 1 de Brino et al. (2011, p. 391). Louis precisou de mais de 50 sessões de treino (compostas de 72 tentativas cada uma) para atingir o critério de aprendizagem, estabelecido como desempenho acima de $90 \%$ de acertos em três sessões sucessivas, no passo final do treino de modelagem. Foram identificados problemas na transição para alguns passos da modelagem (Passos 4 e 8), nos quais o desempenho foi inferior a $70 \%$ de acertos e, embora as relações $\mathrm{AB}$ planejadas tenham sido estabelecidas, o treino foi muito extenso.

O sujeito Guga foi exposto a um procedimento de modelagem do modelo um pouco distinto daquele aplicado a Louis. Para Guga, a modelagem do modelo foi realizada pela substituição gradual de cada modelo (ver detalhes da transformação gradual de estímulos nos passos de modelagem na Figura 3 de Brino et al., 2011, p. 393). Dos 15 passos programados do procedimento de modelagem, Guga avançou rapidamente nos 12 primeiros passos. No entanto, no $13^{\circ}$ Passo, o desempenho decresceu para próximo de $75 \%$ de acertos e assim manteve-se após seis sessões de treino do mesmo passo, de modo que o procedimento foi concluído sem o estabelecimento das relações arbitrárias planejadas (ver
Figura 5 de Cruz et al., 2009, p. 137). A hipótese de que a identidade entre os estímulos modelo e comparação poderia controlar estar controlando as escolhas ao final do treino de modelagem foi testada com Guga, em sessões de avaliação de controle restrito (Brino et al., 2011).

A sessão de avaliação de controle restrito para Guga ocorreu em um passo avançado no protocolo de modelagem e apresentava dois tipos de tentativas: 1) Tentativas do passo final do protocolo de modelagem que avaliavam se o controle relacional arbitrário tinha sido estabelecido no treino e, 2) Tentativas que apresentavam pequenas partes dos estímulos modelo que se mantinham idênticas aos comparações, ainda nas fases finais do protocolo de modelagem de controle de estímulos (ver Figura 4 de Brino et al., 2011, p. 394). Acertar as escolhas no primeiro tipo de tentativas indicava o sucesso do procedimento de modelagem para o estabelecimento de relações arbitrárias; acertar somente as escolhas nas tentativas do segundo tipo indicava a manutenção de controle pela identidade entre modelo e comparação, nestes casos, das pequenas partes do modelo que se mantinham idênticas aos comparações nas fases finais do ensino via modelagem do modelo. Os resultados dos testes de controle restrito de Guga (ver Figura 3 de Brino et al., 2011) indicaram controle por aspectos similares entre modelo e comparações nas relações treinadas em um passo bastante avançado do protocolo de modelagem e ausência de controle quando as partes idênticas não estavam presentes nas tentativas de teste.

No terceiro procedimento de modelagem de controle de estímulos aplicado com o sujeito Raul, neste caso envolvendo transformações graduais nos estímulos de comparação (ver Figura 1 de Brino et al., 2012), muitas sessões de treino foram necessárias para a demonstração do critério de aprendizagem em todos os passos do protocolo de treino. Além disso, diminuições bruscas de desempenho na transição entre alguns passos foram também observadas. Para Raul, assim como ocorreu com Guga, testes de controle restrito foram aplicados para avaliar se elementos similares que se mantinham nos modelos e comparações em passos avançados do treino ainda controlavam o responder (ver Figuras 2 e 3 de Brino et al., 2012). Os resultados nesses testes indicaram que Raul respondia sob controle de relações de identidade e não de relações arbitrárias, pelo menos na maior parte dos passos da modelagem (ver Figura 5 de Brino et al., 2012). Intervenções nos passos finais após a detecção de controle restrito nos testes (detalhes dessas intervenções em Brino et al., 2012) produziram aquisição de desempenho em relações entre estímulos aparentemente arbitrárias. Ainda assim, o treino para o estabelecimento do repertório planejado foi muito extenso e gerou topografias de controle de estímulos inconsistentes, observadas pelas quedas de desempenho em alguns passos de transformação gradual dos estímulos de comparação. 


\section{7) Alternância de contexto de exclusão e tentativa e} erro

Uma estratégia que poderia facilitar o ensino de relações arbitrárias é o procedimento de exclusão. Segundo Dixon (1977), o responder por exclusão caracteriza-se pela escolha de um estímulo de comparação novo ou indefinido, em detrimento de estímulos familiares ou definidos, quando um estímulo novo é apresentado como modelo.

Drácula, um macaco-prego adulto com extensa experiência em emparelhamento ao modelo por identidade, foi submetido ao procedimento de exclusão com o objetivo de ensiná-lo relações condicionais arbitrárias, em uma replicação do Estudo 1 de Brino, Assumpção, Campos, Galvão e McIlvane (2010).

Foi usado o procedimento de emparelhamento ao modelo com atraso, por identidade e arbitrário. A linha de base para a exclusão era composta por nove relações condicionais de identidade, apresentadas em tentativas com nove comparações como escolhas. O estabelecimento dessa linha de base ocorreu de forma gradual, iniciando-se o treino com tentativas com três escolhas e, alcançado um alto índice de acertos, aumentando-se o número de escolhas para sete e, posteriormente, para nove. Depois de estabelecida a linha de base de identidade, iniciou-se o treino em contexto de exclusão de um par de relações condicionais arbitrárias, A-B, e sua simétrica B-A. Nesse treino, uma das relações de identidade era substituída por tentativas A1B1 e B1A1, que eram alternadas com as tentativas de oito relações de identidade. Após o sujeito alcançar o critério de $85 \%$ de acertos em duas sessões consecutivas, com erros distribuídos em diferentes relações, um novo par de relações arbitrárias, A2B2 e B2A2, substituía a relação condicional arbitrária inserida anteriormente, A1B1 e B1A1. Quando alcançado o critério acima descrito, era realizado um teste para avaliar se o treino por exclusão havia produzido aprendizagem dos dois pares de relações arbitrárias $\mathrm{AB}$ e $\mathrm{BA}$, fora do contexto de exclusão, em sessão composta apenas por tentativas das novas relações $\mathrm{AB}$ e BA, na ausência dos $\mathrm{S}$ familiares das relações de identidade.

Os resultados do teste demonstraram que o treino dos pares de relações arbitrárias (AB e $\mathrm{BA}$ ) em contexto de exclusão não produziu aprendizagem das relações, mesmo em sessões compostas por oito estímulos de comparação negativos (S-), que supostamente favoreceriam o estabelecimento de controle por seleção (Sidman, 1987). Para as relações A1B1 e A2B2, Drácula escolheu corretamente em 2 e 4 num total de 6 tentativas, respectivamente. Para as relações B1A1 e B2A2, escolheu corretamente em 3 e 6 , de um total de 6 tentativas, respectivamente. Embora se possa interpretar que ele tenha aprendido a relação B2A2, as escolhas de B2 e A2 são provavelmente o produto de preferência e não de controle condicional porque para a relação B1A1, Drácula escolheu corretamente em apenas $50 \%$ das tentativas.

Com o objetivo de ensinar os primeiros exemplares de relações arbitrárias para Drácula, deu-se continuidade ao experimento, alternando-se sessões de exclusão e sessões de avaliação de aprendizagem das relações, sendo as últimas caracterizadas pelo ensino por tentativa e erro. Mesmo após 13 sequências compostas pelos três tipos de sessão, o sujeito não apresentou a aprendizagem das relações condicionais arbitrárias (ver desempenho na Figura 4 a seguir). Nas sessões de exclusão, o sujeito apresentava altos índices de acerto (entre $90 \%$ e $100 \%$ de acertos), no entanto, quando se mudava o contexto de exclusão para o de treino de tentativa e erro, o seu desempenho decrescia mantendo-se em valores inferiores a $80 \%$ de acertos.

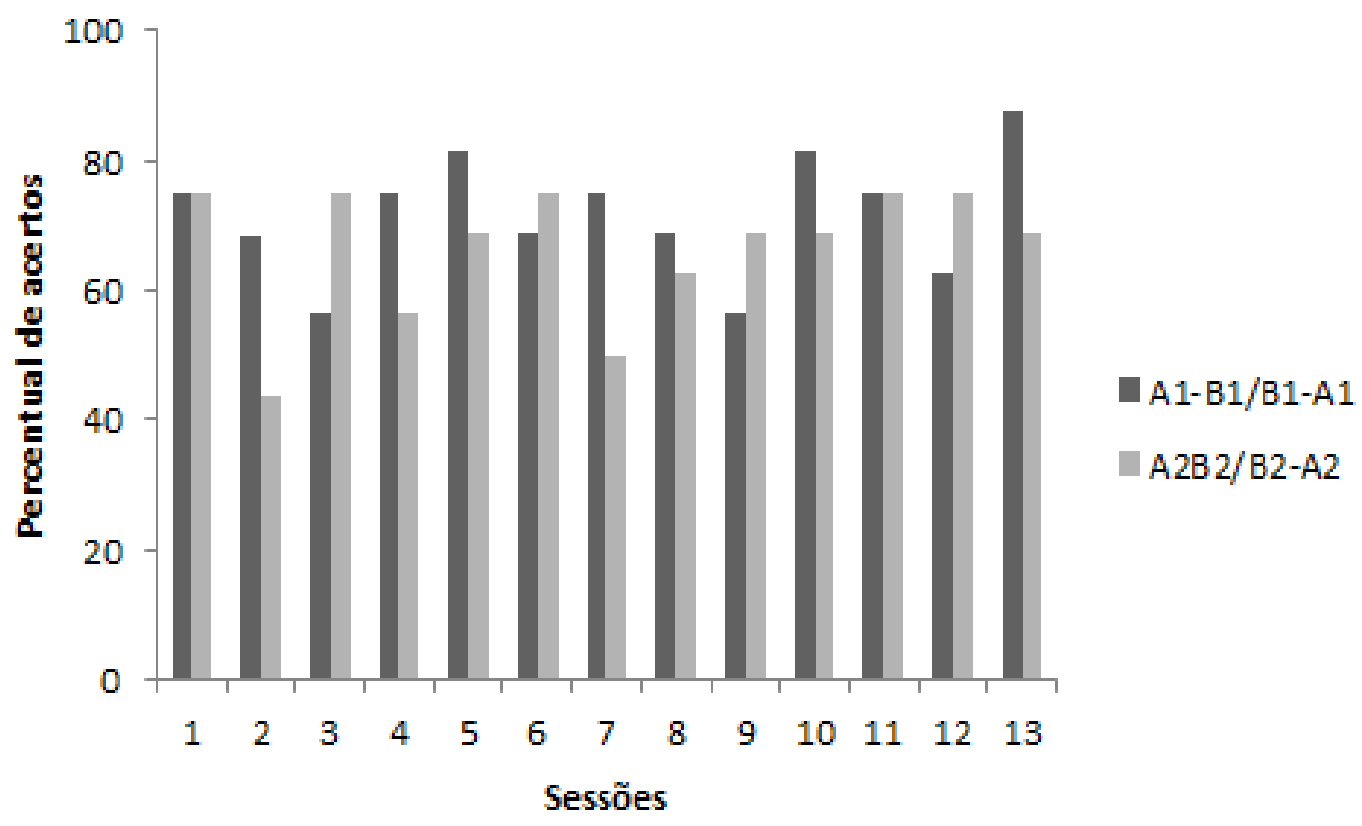

Figura 4. Percentual de acertos em cada sessão de avaliação de aprendizagem por exclusão dos dois pares de relações arbitrárias, AB e BA, para um macacos-prego, Drácula. Essas sessões referem-se à aplicação do procedimento de ensino de relações arbitrárias descrito na Estratégia 7 (Alternância de contexto de exclusão e tentativa e erro). 


\section{CONSIDERAÇÕES FINAIS}

As estratégias usadas em nossos laboratórios integrados de pesquisa básica para o ensino de discriminações condicionais para cães, abelhas e macacos, apresentadas na presente compilação de estudos, mostraram-se pouco eficazes. De modo similar aos dados de Cumming e Berryman (1961, 1965), que estudaram emparelhamento ao modelo com pombos como sujeitos, para os cães utilizados nos estudos aqui relatados, quando as porcentagens de acerto estavam pouco acima do nível do acaso, foi observado controle por variáveis não programadas, como posição ou preferência por estímulo.

Em todas as condições de treino aqui relatadas com os cães, o esquema de reforçamento era contínuo e, portanto, a probabilidade de reforçamento para o responder sob controle de posição ou preferência de estímulo era de $50 \%$. O responder a uma propriedade constante (como a posição do estímulo, por exemplo), quando densamente reforçado, pode produzir certa persistência comportamental. No caso dos estudos com cães descritos aqui, após aprender a responder a uma determinada posição ou aprender a escolher um estímulo específico no treino blocado, por exemplo, o sujeito continuava respondendo ao estímulo de comparação cuja escolha havia sido reforçada na condição anterior, mesmo após mudanças na contingência de reforçamento, como a apresentação de um novo estímulo modelo e de um novo estímulo de comparação como positivo (Urcuioli, 2006).

A persistência comportamental é bastante prejudicial em uma situação de treino de discriminações condicionais, pois o controle condicional exige flexibilidade na escolha da comparação, a depender do estímulo modelo apresentado em cada tentativa. Numa situação de discriminação condicional, a função dos estímulos de escolha muda de acordo com o contexto, e a escolha de um estímulo previamente reforçada pode não mais funcionar na tentativa seguinte da sessão, e assim sucessivamente. Essa variação na função dos estímulos e mudanças nas correlações com o reforçamento confere às situações de discriminações condicionais uma maleabilidade, podendo-se atribuir maior complexidade às relações de controle nessas situações de treino (Debert, Matos, \& Andery, 2006).

Nesse sentido, o uso das estratégias de treino blocado e de treino prévio de discriminações e reversões como pré-requisito para o ensino de escolha condicional, pode ser problemático caso algumas características desses treinos favoreçam a persistência comportamental. Uma forma de se contornar o problema da persistência comportamental a cada reversão de discriminação seria a retirada do estímulo que foi positivo na sessão prévia a cada reversão (Rico, 2006) e também o uso de critérios de aprendizagem que exijam poucas tentativas corretas consecutivas para efetuar as reversões sucessivas ou a alternância de blocos no treino blocado.

Com macacos, os procedimentos de modelagem do estímulo modelo e modelagem dos estímulos de comparação e o uso do contexto de exclusão para o treino de relações condicionais arbitrárias produziu manutenção de repertório de linha de base, sem avanço para a aprendizagem de relações arbitrárias entre estímulos. $\mathrm{Na}$ modelagem, os macacos escolhiam, em quase todos os passos do treino, sob controle de relações de identidade entre elementos dos modelos e comparações que se mantinham no processo de transformação gradual dos estímulos (Brino et al., 2011; Brino et al., 2012). No procedimento de alternância de treino por exclusão e treino por tentativa e erro, um dos macacos, Raul (Brino et al., 2010), aprendeu as tarefas arbitrárias após um treino excessivamente extenso, e Drácula, cujos resultados foram relatados neste trabalho, não adquiriu desempenho mesmo após 13 ciclos de alternância, sendo que cada ciclo somava, pelo menos, três sessões. Os dois macacos escolhiam por exclusão, mas a aprendizagem das novas relações não foi um resultado do treino. Além disso, o treino por tentativa e erro com apenas duas escolhas, aplicado com Drácula, não foi suficiente para que o sujeito apresentasse $90 \%$ de acertos ou mais em sessões com apenas duas relações, em que o nível do acaso é de $50 \%$ de acertos, sugerindo que o descarte dessa característica de procedimento, o uso de duas escolhas (ver Sidman, 1987), é fundamental para produzir topografias de controle de estímulos coerentes em não humanos.

Alguns estudos mostraram que abelhas podem aprender discriminações condicionais entre estímulos visuais (Brown et al., 1998; Giurfa et al., 2001; Moreno, de Souza, \& Reinhard, 2012) e entre aromas e cores (Srinivasan, Zhang, \& Zhu, 1998). No entanto, os relatos na série de estudos descritos neste trabalho e no estudo de Moreno et al. (2012), conduzido com Apis mellifera e Melipona Mruvifentris, são negativos ou inconclusivos.

Com macacos, nos poucos estudos que envolvem o treino e teste de aprendizagem de relações arbitrárias entre estímulos, usualmente informações insuficientes são apresentadas sobre o processo de aquisição da linha de base. Por exemplo, no estudo de D'Amato, Salmon, Loukas e Tomie (1985) foram feitos testes de simetria e transitividade com seis macacos-prego (Cebus apella), com resultados negativos para as relações simétricas e positivos para as transitivas. No que concerne ao estabelecimento da linha de base, os autores apenas afirmam que, para quatro dos sujeitos, o experimento havia partido de um estudo prévio no qual os macacos haviam recebido um treino extensivo em tarefas de emparelhamento de acordo com o modelo. Para os outros dois sujeitos, os autores relatam apenas que eles demoraram 3400 e 1300 tentativas para adquirirem o desempenho, o que sugere dificuldade no estabelecimento do repertório.

Em outro estudo que envolveu o treino de relações arbitrárias e testes de relações simétricas em macacos rhesus e babuínos, Sidman e colaboradores (1982) descreveram características do treino de linha de base, inclusive diferenças nos protocolos de treino de acordo com as necessidades de cada sujeito, mas, na seção de resultados, apresentaram somente os desempenhos nas sessões de teste. Relataram que a linha de base foi adquirida e que, nos testes, o desempenho de linha de base manteve-se acima de $90 \%$ de acertos. No entanto, não há alusão ao processo de aquisição da tarefa, o que não nos 
permite inferir se o processo foi demorado ou não. Ainda assim, o fato de que protocolos distintos tenham sido aplicados a diferentes sujeitos nos indica que um procedimento padrão, previamente definido, precisou ser revisto. Concluindo, os dois estudos citados não ofereceram descrições do procedimento e do processo de aquisição de repertório de discriminações condicionais que poderiam nos guiar sobre a decisão de se aplicar ou não os procedimentos de treino descritos.

Em relação a cães, sabe-se que são capazes de responder sob controle discriminativo de estímulos visuais em procedimentos de discriminações simples (e.g., Aust, Range, Steurer, \& Huber, 2008; Range, Aust, Steurer, \& Huber, 2008; Zaine, Domeniconi, \& Costa, 2014), e de discriminações condicionais de identidade (Kaminski et al., 2009); além disso, cães são capazes de responder sob controle de relações arbitrárias entre estímulos auditivos e estímulos visuais (Kaminski, et al., 2004; Pilley \& Reid, 2011). No entanto, não há estudos publicados que tenham se dedicado especificamente ao treino de relações arbitrárias do tipo visual-visual a essa espécie e a série de experimentos aqui descritos produziram resultados negativos.

Neste trabalho, algumas estratégias alternativas, como reversões sucessivas de discriminações simples mostraram-se ineficazes e, além disso, há poucos indícios de que venham a produzir melhores resultados em estudos posteriores com cães e abelhas, e também macacos (Goulart et al., 2003). Por outro lado, consideramos a hipótese de que outras técnicas, como o treino blocado e a escolha forçada, possam ser futuramente adaptadas para estudos com cães e abelhas, tendo em conta que produziram resultados positivos em determinadas tarefas discriminativas com não humanos e não humanos (e.g., de Rose, Hidalgo, \& Vasconcellos, 2013; Mazur, 1984; Saunders \& Spradlin, 1989). Para os macacos, um novo procedimento de modelagem de controle de estímulos baseado no estudo de Rico, Brino, Goulart e Galvão (2015) está sendo adequado e aplicado para o ensino de relações arbitrárias a duas fêmeas de macacos-prego e os resultados de estabelecimento de controle condicional têm sido animadores. Com cães, alguns ajustes nos protocolos experimentais podem produzir diferenças importantes no desempenho deles, por exemplo, a exigência de respostas mais próximas às que a espécie já realiza naturalmente, como a recuperação de objetos, parece ter contribuído para a investigação sobre emergência de repertório simbólico num contexto de discriminações simples (Zaine, Domeniconi, \& de Rose, 2016), quando comparado à exigência de tocar em uma tela de computador sensível ao toque ou de tocar um estímulo com o focinho, e pode abrir um caminho a ser seguido.

Concluindo, o presente trabalho está baseado em uma coletânea de estudos sobre ensino de relações condicionais arbitrárias em cães, macacos e abelhas e os resultados enfatizados demonstram a dificuldade na produção de dados positivos. A justificativa principal para uma coletânea com estas características repousa na aprendizagem necessária para produção futura de resultados positivos ou minimamente na possibilidade de gerar linha de base estável, a partir de novos estudos que envolvam a proposição de novos procedimentos de ensino. As diferentes tentativas sucessivas ao longo dos anos e por diferentes laboratórios e certamente conduzirão ao aprimoramento dos protocolos e dos procedimentos, tanto pelos autores como, especialmente, pelos leitores e demais pesquisadores que se interessem pela área.

\section{DECLARAÇÃO DE CONFLITO DE INTERESSES}

Os autores declaram que não há conflito de interesses relativos à publicação do presente artigo.

\section{CONTRIBUIÇÃO DE CADA AUTOR}

Todos os autores contribuíram igualmente na produção do artigo e, portanto, participaram suficientemente do trabalho para tornar pública sua responsabilidade pelo conteúdo

\section{DIREITOS AUTORAIS}

Este é um artigo aberto e pode ser reproduzido livremente, distribuído, transmitido ou modificado, por qualquer pessoa desde que usado sem fins comerciais. O trabalho é disponibilizado sob a licença Creative Commons 4.0 BY-NC.

\section{(cc) $\mathrm{BY}-\mathrm{NC}$}

\section{REFERÊNCIAS}

Augustson, K. G., \& Dougher, M. J. (1991). Teaching conditional discrimination to young children: Some methodological successes and failures. Experimental Analysis of Human Behavior Bulletin, 9(2), 21-24.

Aust, U., Range, F., Steurer, M., \& Huber, L. (2008). Inferential reasoning by exclusion in pigeons, dogs, and humans. Animal Cognition, 11(4), 587-597. doi: 10.1007/s10071-008-0149-0

Barros, R. S, Galvão, O. F., \& McIlvane, W. J. (2002). Generalized identity matching-to-sample in Cebus apella. The Psychological Record, 52(4), 441-460.

Brino, A. L. F., Assumpção, A. P. B., Campos, R. S., Galvão, O. F, \& McIlvane, W. J. (2010). Cebus cf. apella exhibits rapid acquisition of complex stimulus relations and emergent performance by exclusion. Psychology \& Neuroscience, 3(2), 209-215. doi: 10.3922/j.psns.2010.2.010

Brino, A. L. F., Barros, R. S., Galvão, O. F., Garotti, M., Cruz, I. R. N., Santos, J. R., Dube, W. V., \& McIlvane, W. J. (2011). Sample stimulus control shaping and restricted stimulus control in capuchin monkeys: A methodological note. Journal of the Experimental Analysis of Behavior, 95(3), 387-398. doi: 10.1901/jeab.2011.95-387

Brino, A. L. F., Galvão, O. F., Barros, R. S., Goulart, P. R. K., \& McIlvane, W. J. (2012). Restricted stimulus control in stimulus control shaping with a capuchin monkey. Psychology \& Neuroscience, 5(1), 83-89. doi: 10.3922/j.psns.2012.1.11

Brino, A. L. F., Galvão, O. F., Picanço, C. R., Barros, R. S., Souza, C. B., Goulart, P. R., \& McIlvane, W. J. 
(2014). Generalized identity matching-to-sample after multiple-exemplar training in capuchin Capuchin monkeys. The Psychological Record, 64(4), 693-702. doi: 10.1007/s40732-014-0035-x

Browder, D. M., \& Lalli, J. S. (1991). Review of research on sight word instruction. Research in Developmental Disabilities, 12(3), 203-228. doi: 10.1016/08914222(91)90008-G

Brown, M. F., McKeon, D., Curley, T., Weston, B., Lambert, C., \& Lebowitz, B. (1998). Working memory for color in honeybees. Animal Learning \& Behavior, 26(3), 264-271. doi: 10.3758/BF03199220

Costa, T. D. (2008). Repetidas mudanças de discriminações simples e formação de classes funcionais em animais. (Tese de Doutorado), Universidade Federal do Pará, Belém.

Cumming, W. W., \& Berryman, R. (1961). Some data on matching behavior in the pigeon. Journal of the experimental analysis of behavior, 4(3), 281.

Cumming, W. W., \& Berryman, R. (1965). The complex discriminated operant: Studies of matching-to-sample and related problems. In D. I. Mostofsky (Ed.), Stimulus Generalization (pp. 284-330). Stanford, CA: Stanford University Press.

Cruz, I. R. N., Kataoka, K. B., Costa, A. C. O., Garotti, M. F., Galvão, O. F., \& Barros, R. S. (2009). Modelagem do estímulo-modelo para estabelecer relações condicionais arbitrárias em macacos-prego (Cebus apella). Arquivos Brasileiros de Psicologia, 61(3), 128-139.

Dahás, L. J. D. S., Brasiliense, I. C. D. S., Barros, R. D. S., Costa, T. D., \& de Souza, C. B. A. (2010). Formação de classes funcionais em cães domésticos (Canis familiaris): uma abordagem da aquisição de comportamento pré-simbólico. Acta Comportamentalia, 18(3), 317-346.

D’Amato, M. R., Salmon, D. P., Loukas, E., \& Tomie, A. (1985). Symmetry and transitivity of conditional relations in monkeys (Cebus apella) and pigeons (Columba livia). Journal of the Experimental Analysis of Behavior, 44(1), 35-47. doi: 10.1901/jeab.1985.4435

de Rose, J. C. (1993). Classes de estímulos: implicações para uma análise comportamental da cognição. Psicologia: Teoria e Pesquisa, 9(2), 283-303.

de Rose, J. C., \& Bortoloti, R. (2007). A equivalência de estímulos como modelo do significado. Acta Comportamentalia, 15, 83-102.

de Rose, J. C., Hidalgo, M., \& Vasconcellos, M. (2013). Controlling relations in baseline conditional discriminations as determinants of stimulus equivalence. The Psychological Record, 63(1), 85-98. doi: 10.11133/j.tpr.2013.63.1.007

Debert, P., Matos, M. A., \& Andery, M. A. P. A. (2006). Discriminação condicional: definições, procedimentos e dados recentes. Revista Brasileira de Análise do Comportamento, 2(1), 37-52.

Dixon, L. (1977). The nature of control by spoken words over visual stimulus selection. Journal of the
Experimental Analysis of Behavior, 27(3), 433-442. doi: 10.1901/jeab.1977.27-433

Dube, W. V., \& Mcllvane, W. J. (1996). Some implications of a stimulus control topography analysis for emergent stimulus classes. In T. R. Zentall \& P. M. Smeets (Ed.). Stimulus class formation in humans and animals (pp. 197-218). North Holland: Elsevier.

Dugdale, N., \& Lowe, C. F. (1990). Naming and stimulus equivalence. In D. E. Blackman \& H. Lejeune. (Ed.) Behaviour analysis in theory and practice: contributions and controversies. (pp. 115-138). Hillsdale, NJ, England: Lawrence Erlbaum Associates, Inc.

Galvão, O. F., Barros, R. S., Santos, J. R., Brino, A. L. F., Brandão, S., Lavratti, C. M., Dube, W. V., \& McIlvane, W. J. (2005). Extent and limits of the matching concept in Cebusapella: A matter of experimental control? The Psychological Record, 55(2), 219-232.

Galvão, O. F., Soares Filho, P. S. D., Barros, R. S., \& Souza, C. B. A. (2008). Matching-to-sample as a model of symbolic behavior for bio-behavioral investigations. Reviews in Neurosciences, 19(2-3), 149-156. doi: 10.1515/REVNEURO.2008.19.2-3.149

Gil, M. S. C. A., Oliveira, T. P., \& McIlvane, W. J. (2011). Conditional discrimination by preverbal children in an identity matching-to-sample task. The Psychological Record, 61(3), 327-340.

Giurfa, M., Zhang, S., Jenett, A., Menzel, R., \& Srinivasan, M.V. (2001). The concepts of 'sameness' and 'difference' in an insect. Nature, 410(6831), 930932. doi: $10.1038 / 35073582$

Goulart, P. R., Galvão, O. F., \& Barros, R. S. (2003). Busca de formação de classes de estímulos via procedimento de reversões repetidas de discriminações simples combinadas em macaco-prego (Cebus appela). Interação em Psicologia, 7(1), 109-119. doi: 10.5380/psi.v7i1.3213

Iversen, I. H., Sidman, M., \& Carrigan, P. (1986). Stimulus definition in conditional discriminations. Journal of the Experimental Analysis of Behavior, 45(3), 297-304. doi: 10.1901/jeab.1986.45-297

Kaminski, J., Call, J., \& Fischer, J. (2004). Word learning in a domestic dog: Evidence for "fasting mapping". Science, 304(5677), 1682-1683. doi: 10.1126/science.1097859

Kaminski, J., Tempelmann, S., Call, J., \& Tomasello, M. (2009). Domestic dogs comprehend human communication with iconic signs. Developmental Science, 12(6), 831-837. doi: 10.1111/j.14677687.2009.00815.x

Kastak, D., \&Schusterman, R. (1994). Transfer of visual identity matching-to-sample in two California sea lions (Zalophus californianus). Animal Learning \& Behavior, 22(4), 427-435. doi: 10.3758/BF03209162

Laws, K. R. (2013). Negativland - a home for all findings in Psychology. BMC Psychology, 1 (1), 2. doi: 10.1186/2050-7283-1-2

Mazur, J. E. (1984). Tests of an equivalence rule for fixed and variable reinforcer delays. Journal of Experimental 
Psychology: Animal Behavior Processes, 10(4), 426. doi: 10.1037/0097-7403.10.4.426

McIlvane, W. J., \& Dube, W. V. (1992). Stimulus control shaping and stimulus control topographies. The Behavior Analyst, 15(1), 89-94.

McIlvane, W. J., \& Dube, W. V. (2003). Stimulus control topography coherence theory: Foundations and extensions. The Behavior Analyst, 26(2), 195-213.

Moreno, A. M., de Souza, D. G., \& Reinhard, J. (2012). A comparative study of relational learning capacity in honeybees (A. mellifera) and stingless bees ( $M$. rufiventris). PLoS ONE,7(12), e51467. doi: 10.1371/journal.pone.0051467

Oden, D. L., Thompson, R. K. R., \& Premack, D. (1988). Spontaneous transfer of matching by infant chimpanzees (Pan troglodytes). Journal of Experimental Psychology: Animal Behavior Processes, 14(2), 140-145. doi: 10.1037/0097-7403.14.2.140

Pessotti, I. (1981). Aprendizagem em abelhas. VI Discriminação condicional em Meliponarufiventris. Revista Brasileira de Psicologia, 41(4), 681-693.

Pilley, J. W., \& Reid, A. K. (2011). Border collie comprehends object names as verbal referents. Behavioral Processes, 86(2), 184-195. doi: 10.1016/j.beproc.2010.11.007

Range, F., Aust, U., Steurer, M., \& Huber, L. (2008). Visual categorization of natural stimuli by domestic dogs. Animal Cognition, 11(2), 339-347. doi: 10.1007/s 10071-007-0123-2

Rico, V. V. (2006). Persistência comportamental e topografia de controle de estímulos coerente em treino de discriminação simples e escolha condicional por identidade ao modelo com quarto escolhas em macacos-prego. (Dissertação de Mestrado), Universidade Federal de do Pará, Belém.

Rico, V. V., Brino, A. L. F., Goulart, P. R. K., \& Galvão, O. F. (2015). Da discriminação simples à condicional: Um programa de ensino para macacos-prego. Revista Brasileira de Análise do Comportamento, 11, 37-52.

Santos, J. R. D. (2003). Cognição animal: identidade generalizada e simetria em macaco-prego (Cebus apella). (Dissertação de Mestrado), Universidade Federal do Pará, Belém.

Saunders, K. J., \& Spradlin, J. E. (1989). Conditional discrimination in mentally retarded adults: The effect of training the component simple discriminations. Journal of the Experimental Analysis of Behavior, 52(1), 1-12. doi: 10.1901/jeab.1989.52-1

Sidman, M. (1987). Two choices are not enough. Behavior Analysis, 22, 11-18.

Sidman, M., Rauzin, R., Lazar, R., Cunningham, S., Tailby, W., \& Carrigan, P. (1982). A search for symmetry in the conditional discrimination of rhesus monkeys, baboons, and children. Journal of the Experimental Analysis of Behavior, 37(1), 23-44. doi: 10.1901/jeab.1982.37-23.

Sidman, M., \& Stoddard, L. T. (1967). The effectiveness of fading in programming a simultaneous form discrimination for retarded children. Journal of the
Experimental Analysis of Behavior, 10(1), 3-15. doi: 10.1901/jeab.1967.10-3.

Sidman, M., \& Tailby, W. (1982). Conditional discrimination vs. matching to sample: An expansion of the testing paradigm. Journal of the Experimental Analysis of Behavior, 37(1), 5-22. doi: 10.1901/jeab.1982.37-5.

Srinivasan, M. V., Zhang, S. W., \& Zhu, H. (1998). Honeybees link sights to smells. Nature, 396(6712), 637-638. doi: 10.1038/25272.

Urcuioli, P. J. (2006). Responses and acquired equivalence classes. In E. A. Wasserman \& T. R. Zentall (Eds.). Comparative cognition: Experimental explorations of animal intelligence (pp. 405-421). New York: Oxford University Press.

Zaine, I. (2015). Sensibilidade a dicas sociais humanas e comportamentos emergentes em cães domésticos (Canis familiaris). (Tese de Doutorado), Universidade Federal de São Carlos, São Carlos.

Zaine, I., Domeniconi, C., \& Costa, A. R. A. (2014). Exclusion performance in visual simple discrimination in dogs (Canis familiaris). Psychology and Neuroscience 7(2), 199-206. doi: 10.3922/j.psns.2014.014.

Zaine, I., Domeniconi, C., \& de Rose, J. C. (2016). Exclusion performance and learning by exclusion in dogs. Journal of the experimental analysis of behavior, 105(3), 362-374.

Zygmont, D. M., Lazar, R. M., Dube, W. V., \& McIlvane, W. J. (1992). Teaching arbitrary matching via sample stimulus-control shaping to young children and mentally retarded individuals: A methodological note. Journal of the Experimental Analysis of Behavior, 57(1), 109-117. doi: 10.1901/jeab.1992.57-109.

Submetido em: 27/02/2019 Aceito em: 03/06/2019 